\title{
Award-Winning Mentors See Democratization as the Future of Undergraduate Research
}

\begin{abstract}
The authors embarked on a study to determine what is on the horizon for undergraduate research (UR) for the future. They reviewed the literature to identify current trends and asked 33 faculty recipients of awards for UR commitment and expertise about their perceptions of UR in the next five to ten years. Results suggest that the next decade may bring more democratization of UR such as greater access to research opportunities for undergraduates from historically underserved groups, those from nontraditional populations, and those with below-average or average academic performance histories. Results also indicate strengthened mentor-student relationships across national and international borders due to enhanced communications technologies.
\end{abstract}

Keywords: mentoring, nontraditional students, undergraduate research in the curriculum, underrepresented students

The practices, models, and contexts of undergraduate research have changed dramatically in the last decade, largely as a consequence of the acknowledgment of undergraduate research (UR) as a "high-impact practice" directly correlated with student retention, student graduation rates, and key learning outcomes (Brownell and Swaner 2010; Kuh 2008; Lopatto 2010). Because of the array of valuable skills and dispositions developed as a result of engagement in UR, mentored scholarly work has spread to every academic discipline. This expansion has not only changed the dimensions of undergraduate inquiry to include diverse fields of study and various epistemologies but also the forms and models of student scholarship. UR is now carried out in large, tiered collaborations and research-rich courses across the curriculum, as well as in traditional one-on-one and small-group mentoring structures. It has successfully evolved in these ways at myriad types of institutions of higher education worldwide (Shanahan et al. 2015). As the significant benefits of mentored scholarly experiences continue to be uncovered, the years ahead promise continued growth and innovation in what has traditionally been known as "undergraduate research."

This research suggests that the next decade may bring further democratization of UR. Anticipated is greater access to research opportunities for undergraduates from historically underserved groups-from underrepresented minorities and first-generation college students to those with average, and even below-average, academic records. Such access often be- gins in the curriculum, when faculty build original scholarly experiences into courses, introducing diverse groups of students to the thrill of discovery and creation of knowledge. Access to UR may be further facilitated by the use of communication technologies that bring students and mentors together with enhanced efficiency across geographic distance. Broadening participation to students who traditionally would not have had mentored research experiences has been a paradigm shift in UR mentoring — an exciting development that is expected to continue.

\section{Purpose and Method of the Study}

This study sought to envision what is in store for UR for the future, so that faculty and administrators may plan for necessary resources and consider their approaches to ensure equitable, inclusive, and high-quality UR in the next decade and beyond. To gauge what may be coming in the practice of UR, the authors first reviewed the literature on UR to identify current trends that are becoming institutionalized and therefore may have staying power, such as embedding original research experiences in the curriculum (Shanahan et al. 2015). Perceptions of leading international UR mentors across the disciplines-faculty who have been recognized for their UR commitment and expertise-then were sought. A similar methodology was employed by Mitten and Ross (2016), who interviewed award-winning college teachers to inform higher education faculty and administrators about the resources and praxes that may benefit future faculty.

This study is part of a larger, multi-institutional research project that is aimed at defining and describing effective UR mentoring, which has been shown to be essential to the overall success of UR (Davis 2007; Handelsman et al. 2005; Kuh 2008; Malachowski 1996; Merkel and Baker 2002; National Academy of Sciences, National Academy of Engineering, and Institute of Medicine 1997; Osborn and Karukstis 2009; Shore 2005; Thiry and Laursen 2011; Wenzel 1997; Yaffe, Bender, and Sechrest 2012). The authors sought to discover which aspects of UR are considered by effective mentors to work well and to be worthy of support for continuation and expansion. Their ideas about successful practices that should progress into the future are part of a developing pedagogy of UR mentoring that may guide the professional development of mentors. In the mode of Bain's (2004) What the Best College Teachers Do and Mitten and Ross's (2016) study of professors 
at research-intensive universities who won awards for excellence in teaching, people recognized for UR mentoring were asked for their reflections on what contributed to that success and what they expect will be sustained in the coming years. It was assumed that award-winning mentors would be good predictors of the future of UR especially because they were acknowledged for their sustained and documented mentoring achievements and forward-thinking praxes.

One way that UR mentors are identified as effective is through institutional and national awards for their mentoring work. Their own students and colleagues are most often those who nominate UR mentors for such awards, indicating a successful record of guiding students in scholarly work. The interdisciplinary group of five U.S. and U.K. researchers conducted 33 in-depth, qualitative, key-informant interviews with faculty who had recently won institutional or national awards for their work of mentoring undergraduate researchers. Besides the recognition they received for successful and innovative work in UR, the interviewees were selected for diversity in gender, academic discipline, country (and region of the country for those in the United States), type of institution, and professional rank. Interviewed were men and women (45 percent male, 55 percent female) in all ranks (10 percent assistant professor, 60 percent associate professor, 30 percent professor), across many disciplines (10 percent health, 25 percent STEM, 25 percent arts and humanities, 40 percent social sciences), and from different English-speaking regions of the world ( 3 percent Canada, 7 percent Australia, 10 percent U.K., 80 percent U.S.). They work in a variety of higher education institutions-from large, doctoral-granting universities to small liberal arts colleges (60 percent at institutions with more than 15,000 students; 20 percent at institutions with 5,000-15,000 students; and 20 percent at institutions with fewer than 5,000 students). The authors believed that such a diverse group of successful UR mentors could offer important insights into the current environment and future possibilities for UR mentoring.

A qualitative study design was selected that would allow new perspectives on UR mentoring to be discovered through open-ended interviews. A 10-question interview guide was developed to promote internal consistency of the data. The questions were designed to help bring forth rich, detailed reflections. The interview transcripts were analyzed to discover emerging patterns via Strauss and Corbin's (1990) grounded theory approach to open coding. Among other questions, participants were asked: "In what ways do you think the practice of mentoring undergraduate research might change in the next five to ten years?"

The 33 interviewees offered a variety of scenarios about the current UR trends that they believed and hoped would continue, and proposed ideas for meeting the challenges that lie ahead. The most prominent themes focused on expansion of and more equitable access to UR:

- 42 percent of the award-winning mentors prioritized recruitment of student-researchers from historically underserved populations, including underrepresented minorities, first-generation students, and low-income students;

- 27 percent spoke of the value of involving "regular," or nonhonors, students in UR;

- 55 percent predicted greater inclusion of diverse students, from those in their first year to graduating seniors, in curriculum-based scholarly projects; and

- 36 percent anticipated increased involvement in research of students and professors around the world through the use of communication technologies.

In many cases, the interview responses resonated with findings in the literature about recruiting and mentoring students from historically underserved groups, extending invitations to participate in UR to those with average grades, and embedding research in undergraduate curricula. Discussion of those themes in the following sections note the connections between the literature and the results of this study. Participant remarks about students and mentors collaborating on UR across geographic distances using technology have not shown up prominently in the literature except as part of broader research on teaching practices for online and hybrid courses. Systematic study of distance mentoring of UR has not yet occurred, even though some interviewees are performing distance mentoring; this may be a fruitful opportunity for future research to identify best practices of distance mentoring and to expand the options for participating in UR through online collaborations.

Taken together, the interview responses point to the democratization of the high-impact practice of UR. Participants expressed hope that current trends to involve underrepresented students and students with average grades would continue to progress, and that course-based projects and communication technologies would allow UR opportunities to reach many more students.

\section{Projected Growth in Undergraduate Research}

All 33 of the interviewees expected to see continued growth in the numbers of students and faculty involved in UR. They spoke of its profound benefits for students and the broadening recognition of those benefits across disciplines and institutions worldwide. A psychology professor at a primarily undergraduate institution (PUI) in the southeastern United States called UR "a pinnacle practice," conveying the consensus opinion among the 33 interviewees that UR is one of the most valuable experiences in which students can par- 
ticipate-a point substantiated in the literature of the past two decades (Brownell and Swaner 2010; Kuh 2008; Lopatto 2010; Malachowski 1996; National Academy of Sciences 1997; Shellito et al. 2001). For that very reason, a computer engineer at another PUI projected that student participation in faculty-mentored research would "become more and more paramount."

According to a professor of architecture at a research-intensive university in the western United States, university administrators have heard the message about UR as a high-impact practice and now see it as a means of providing higher quality educational experiences and improving student motivation. She observed that institutional shifts toward supporting UR across the disciplines reflect agreement between administrators and faculty about the value of the practice:

- "It's coming from the top down, but also I think absolutely from the bottom up. There is an increasing number of young faculty who want to ... involve students in their own research or their own creative work."

Several other interviewees indicated that continued growth in UR will emanate mainly from faculty-from experienced UR mentors who have seen students thrive in research; from new members of the professoriate who had research experiences themselves as undergraduates or otherwise recognize the practical benefits of integrating their scholarship and teaching; and from faculty in disciplines new to UR who are discovering how it can work in their areas of study, particularly in the arts, education, and humanities. A professor of integrated studies (an interdisciplinary program) at a research-intensive university in the midatlantic United States foresees a reciprocal relationship between students and faculty involved in UR: the more students request the opportunity to collaborate with faculty on research, the more faculty will see it as an "important endeavor" and vice versa. A faculty member in physical education at a doctoral-granting institution in Canada expressed similar expectations for the growth of UR as a result of faculty interest. He has seen

- "moderate research programs where they don't have tons of funding for post docs ... have lots of opportunities [for involving undergraduates in research] ... A lot of us are starting to see the great resources that we have available in terms of undergraduate students who are very driven and motivated, and who can bring a lot to a lab."

Steady expansion of UR participation in the United States has been demonstrated by the threefold increase in the number of institutional members of the Council on Undergraduate Research (CUR) in the past 20 years (to 683 colleges and universities), as well as steep escalations in participation in CUR workshops on institutionalizing UR (Council on Undergraduate Research 2016; Karukstis 2012). Based on such data and direct experience in leadership in CUR over two de- cades, Karukstis $(2012,17)$ stated, "There is no doubt that the movement to institutionalize undergraduate research has swept this country."

That said, Karukstis (2012) and other scholars have called for workload credit for mentoring, more time to do research with undergraduates, compensation (especially for summer mentoring), and supportive promotion and tenure guidelines so that UR can continue to expand (Malachowski et al. 2014; Rowlett, Blockus, and Larson 2012). Several interviewees also called for improved institutional capacity and more mentoring support for the growing numbers of students in UR- "in order to meet the demand sustainably," as one longtime mentor stated. An education professor in Australia put it this way:

- "The question is, how [do] you take these amazing experiences and make them available to more people? How do you mainstream the activity ... so a bigger proportion of students can have as similar as possible an experience?"

Some interviewees thought that making UR opportunities more broadly available would be essential to helping students achieve their goals beyond their bachelor's degree. They expected that not only graduate and professional schools but also employers in a wide range of fields would seek out candidates with research experience. A faculty member in economics at a large, public research university said simply, "Employers are more and more expecting undergraduates or graduates to have [research] experience." An English professor at a regional public university has found UR to be so important to developing students' future opportunities that she thinks "schools that don't have strong undergraduate research programs are not going to be able to place their graduates in solid career paths and solid graduate programs."

\section{Democratization of UR for Underrepresented Students}

Fourteen of the thirty-three interviewees spoke of greater inclusion in UR of students from historically underserved populations: students of color, low-income students, and first-generation students. That commitment coincides with findings in the literature about the markedly higher gains for underrepresented minority students who participate in UR (Brownell and Swaner 2010; Gregerman 2009; Jones, Barlow, and Villarejo 2010; Kinzie et al. 2008; Kuh 2008; Kuh and O'Donnell 2013; Osborn and Karukstis 2009; Locks and Gregerman 2008). A faculty member in the College of Education at a comprehensive, regional university in the northeastern United States referred to supporting underrepresented minority and first-generation students in UR as a "best practice" in higher education. She predicted that in the next decade, more and more faculty will participate in "holistic mento- 
ring, actually engaging students on that one-on-one level" and "supporting students from underrepresented populations" in high-impact practices, as they see successful disciplinarily models for it.

A biology professor at an economically and ethnically diverse PUI in the southwestern United States pointed out that "not everyone is coming from a prep school, so thinking about how students can be successful from the moment they enter the university" is imperative to retaining students, particularly those interested in science:

- "We often find that it is an underrepresented group of first-generation college students and underrepresented minorities that don't persist in the sciences, but we also know at the same time that students who are involved in research labs do persist, so [we are] trying to find a ... sustainable way of engaging a broader diversity of students in the kind of work that real scientists do... What if we bring in younger students and the more at-risk students? [What] if we started integrating them into our research labs? How might that make a difference in the lives of the students?"

An English professor who recruits diverse undergraduate researchers not only from classes but also from the university's Center for Multicultural Affairs to ensure a diverse research team said that UR offers underrepresented students "an edge." UR "gives students the tools that they would've gotten years ago only if they went to grad school, which is itself a privileged decision." She noted the "social justice aspect" of UR in that it provides scholarly opportunities for students regardless of socioeconomic class-something that otherwise would not happen. For those reasons, she said she expects in the near future that UR programs will be high-profile indicators of quality and equity for institutions of higher education. That position has been discussed extensively in the literature on undergraduate education since at least 1998, when the Boyer Commission called on higher education faculty to make inquiry-based learning the standard throughout the student lifecycle, with opportunities for conducting meaningful research from the first to final year for all students. The call to ensure that UR opportunities are welcoming and supportive of all students was made even clearer by Kuh (2008) and Gregerman (2009), who showed that the benefits of UR participation accrue at a greater rate for underrepresented students than for students from advantaged backgrounds.

\section{Democratization of UR for "Average" Students}

Nine mentors (27 percent) believed that awareness of high-impact practices has been increasing among their colleagues, and, as a result, a greater diversity of students will be offered opportunities to participate in UR. In addition to wel- coming more economic, racial, and ethnic diversity among undergraduate researchers, interviewees anticipated that students with a wider range of grades will also be participating in UR. A notable theme in the interviews was the belief that a student's course grades are not reliable predictors of success in UR. A neuroscientist who teaches at a PUI in the southeastern United States described working well with C-average students in her lab, noting,

घ "I try to reach out to people who wouldn't otherwise [get the chance to do research]. Once you get over that idea [that GPA correlates with research ability] it allows you to open up to a much wider range of students."

A faculty member in mathematics at a public, comprehensive university in the southeastern United States also made a case for engaging undergraduate researchers who are not straight-A students:

- "I think people are starting to acknowledge that undergraduate research has a benefit not just for these superstar students who traditionally have been the ones who engage, but also students who are maybe not getting on. Maybe they are C students or B students who also would benefit from these experiences. And so I think part of the practice is, how do we engage a broader network? Because in some sense those students may be the ones who need the experience more than the student who has already been successful ... I think the question is, how do the mentorship practices that are developing-or the systems that are now in place in the U.S. that are mainly designed to serve those top students-how do they need to be modified to serve regular students?"

Positive research experiences with students who have average and below-average academic records have been supported in the research literature about the benefits of UR. Kinkead $(2003,11)$ wrote that honors programs "are natural sites for undergraduate research," but, "at what some might see as the opposite end of the continuum from honors students, at-risk students benefit from the same advantages." "Regular" and "at-risk" students have shown gains in valuable knowledge and practice that go well beyond the scope of research-skills development and disciplinary inquiry: "Undergraduate researchers learn tolerance for obstacles faced in the research process, how knowledge is constructed, independence, increased self-confidence, and a readiness for more demanding research" (Lopatto 2010, 28). In moving away from reserving mentored research opportunities for only the "best and brightest" students, mentors have seen their "typical" students, including those who are less engaged in the classroom, thriving in UR. Interviewees indicated that they may actually facilitate more gains in terms of student development by working with those whose GPAs would usually preclude them from a research experience. Students with undistin- 
guished academic records were seen by some interviewees as more open to taking necessary risks and less worried about controlling the outcomes than their straight-A peers. As one mentor noted, "I have had some students who were terrible classroom students and very productive researchers."

This finding contradicted data from Jones and Davis (2014) indicating that faculty wanted to work with undergraduate researchers who had first "proven themselves" in the classroom. Interviewees have found that the opportunity to conduct authentic research inspired students who were previously disengaged academically. Students with average and below-average grades were said to become more engrossed in their field of study and motivated to pursue what Kuh (2008) termed "actively contested questions" when they began conducting research. Interviewees concurred with the finding by Lopatto $(2010,30)$ that "a research experience helps one to be a better student."

\section{Democratization of UR in the Curriculum}

When asked about the future of UR, 18 of the interviewees (55 percent) mentioned the increased integration of original, scholarly work in the curriculum. They saw more coursebased UR as a way to scale up a high-impact practice, benefiting a broader array of students as well as mitigating faculty workload. Their attention to research embedded in the curriculum reflects a strong tradition of course-based research skill development particularly in Australia (see especially Willison and O'Regan 2007) and the United Kingdom (most notably by Healey and Jenkins [2009] and Walkington et al. [2011]). The practice of developing scaffolded research/inquiry in the curriculum has been quickly gaining ground in North America as well, especially since the publication of Developing and Sustaining a Research-Supportive Curriculum: A Compendium of Successful Practices (Karukstis and Elgren 2007). One indicator of its growth is that a 2016 CUR Quarterly call for proposals for an issue on UR in the curriculum resulted in so many submissions that the journal editors extended the theme over two issues.

CUR President Susan Larson (2016) noted that among the advantages of embedding research in the curriculum is the scaling up of UR participation within existing teaching loads. That view was also expressed by interviewees in this study. A faculty member in economics at a large public university advocated for expansion of her department's practice of organizing UR mentoring as part of teaching: "I think that type of framework is nice because faculty are getting credit for it. It's really taking up another course that they would have taught." Interviewees explained that, as the demand for mentored UR experiences has increased at all of their institutions, the resources for it, especially in terms of faculty time, cannot keep up with student interest. In several cases, that practical consideration led mentors to integrate research in the curriculum, including in fields not traditionally associated with research, thereby "widening what counts as research," according to a principal lecturer of architecture at a comprehensive university in the United Kingdom. Interviewees reflected on the possibilities for UR in the curriculum that could allow a greater number of students to gain research experience as well as enhance their own pedagogy, a point frequently made in the literature as well (see especially CUR Quarterly 37 [2016], issues 1 and 2).

In addition to creating a more manageable workload for faculty, UR embedded in the curriculum was seen as more equitable for students, as it offers universal access to research opportunities for everyone enrolled in a class. A computer scientist at a private, East Coast university in the United States called for "authentic research embedded in a bunch of courses" so that all students, not just those in the honors program, would have "several research experiences each semester." He explained:

- "Within the regularly scheduled courses ... in lab sciences and even humanities courses, instead of doing the repetitious, same work that was done last year and done before and done before, that there is authentic research now-that there is a research question that ... students work on and that's how they learn ... investigative techniques."

Such ideas reiterated findings in the international literature of recent years on models and principles of research-rich curricula across the disciplines, which propose embedding research or inquiry in every discipline and at each stage of students' courses of study (Brew 2006, 2013; Healey and Jenkins 2009; Healey, Jenkins, and Lea 2014; Karukstis and Elgren 2007; Shanahan 2012; Walkington et al. 2011; Willison 2009, 2012).

In integrating UR in the curriculum, interviewees acknowledged that a shift in emphasis was needed from the research product (such as a peer-reviewed journal article) to the inquiry process (that is, student learning). A mathematician interviewee urged UR mentors to adjust their expectations and objectives accordingly: "The goal needs to be more on the student development side and less on the product." His point was echoed by other interviewees who found that facilitating research experiences for students in the curriculum meant working with a broader range of academic abilities and therefore concentrating on the student-development process more than on the results of the research. They spoke of a need to adjust the expectations of the end-product to a campus-symposium presentation or as supporting data for a professor's research rather than publishable work in its own right. That change in focus need not curtail the benefits of 
UR for students (Larson 2016). For example, Burnette and Wessler (2013) found that UR in a large introductory biology course resulted in student gains similar to those reported in intensive, independent research.

\section{Democratization of UR through the Use of Technology}

In addition to enhancing UR engagement through embedded curricular experiences, the democratization of UR has provoked developments in UR mentoring pedagogies involving technologies to support distance mentoring. By means of online resources and communication technologies, 12 of the interviewees (36 percent) said they were able to increase both the number of students who could be guided through UR experiences and the range of global, interdisciplinary collaborations in which faculty and students engaged. Systematic studies of distance mentoring do not exist in the literature on UR, although there is extensive research on online teaching and learning. Some parallels could be drawn between distance UR mentoring and examples in Conrad and Dunek's (2012) Cultivating Inquiry-Driven Learners: A College Education for the 21st Century, because the authors provided models of effective online interactions that support student inquiry. Their treatment of the topic of distance teaching is not exactly comparable to what the interviewees discussed, however, primarily because Conrad and Dunek wrote about online interactions in distance learning and hybrid courses, whereas the interviewees spoke of the challenges and possibilities offered by technology in connecting individuals in closer mentoring relationships.

The award-winning mentors in this study stressed the importance of the quality of the mentor-mentee relationship. When considering the future of UR, the use of technology in building and sustaining those relationships was frequently mentioned in both positive and negative ways. On the one hand, technology was seen as a potential threat to the quality of the mentoring relationship. A faculty member at a private PUI in the western United States explained:

- "As a Theatre practitioner I care very much about 'liveness,' and about that interpersonal thing that happens when you're in shared time and place. So I am conflicted about [technology]."

However, for other mentors, particularly those who already use technology to enhance their mentoring, there was a positive sense of potential for developing and maintaining mentoring through the use of Internet-based communication technologies.

In recognizing the benefits of directly mentored UR experiences, some interviewees acknowledged that location can be a barrier to student participation. A mathematician in the
United States said that although "personally working with the students is important, it doesn't have to happen at the same place. We could do that over Skype with a broader network of students." A U.K. mentor saw the potential for using technology in UR as a result of the need for computer modeling in bioscience research that is cascading into undergraduate projects. The added benefit is that more students can participate because collaborative research discussed via Skype is "more manageable than having them taking space in the laboratory." A principal lecturer in Australia described using Skype and video-conferencing as standard practice, as her pharmacy students are dispersed across a large geographical area: "I've just got so used to it I don't think anything of it."

Online communications-especially once a face-to-face mentoring relationship was established-have shown promise in extending current mentoring relationships or, as was noted by interviewees, in sustaining those relationships beyond graduation and sometimes leading to further collaborations. A computer scientist in the United States speculated, for example, that in the future, he might have students from another university during a summer REU (Research Experiences for Undergraduates) who may "want to pursue something very close to the research that they did with me over the summer, but [are] unable to find a mentor in their home institution." He said he would hope to continue the mentoring online.

Although greater planning and structuring were perceived to be needed for technology-mediated mentoring, some mentors argued that too much structure might come at the expense of serendipity, wherein developments emerge naturally as a result of proximal mentoring. Others noted the potential for collaborative online spaces to enhance such fortunate experiences, including greater possibilities for problem-solving when team members in multiple locations are involved. For that reason, technology-mediated mentoring has already become a feature of international, multi-institutional networks. An education professor in Australia described a UR experience in which "students were being looked after in their own institution, but were talking to each other [across continents] about their topics." She expected that in coming years, however, "the students might be mentored by an academic in a different country." In sum, the mentor's personal preferences, experience using communication technologies, and to some extent the norms of the particular discipline affected the perception of the potential for online mentoring. Those who saw hope in its potential wanted to broaden participation and share the benefits of UR with a greater number of students.

\section{Conclusion}

Iterative themes in this study have revealed that evolving mentoring practices, which are already democratizing UR, 
resonate with award-winning mentors' hopes for the future: that a greater diversity of students will participate; more disciplines, models, and institutions will be reached; and communication technologies will facilitate new collaborations. As evidenced in the literature as well as the mentor interviews, these current trends have already extended the reach of mentored UR, leading to the inclusion of underrepresented students and a greater number of students overall. The heightened possibilities for collaboration through online mentoring, the new perspectives offered by a richer diversity of students, and the redesign of curricula to reflect an inquiry focus may lead to additional positive outcomes related to UR as a high-impact practice.

\section{Acknowledgment}

This study was supported by the research seminar Excellence in Mentoring Undergraduate Research at Elon University's Center for Engaged Learning (2014-2016).

\section{References}

Bain, Ken. 2004. What the Best College Teachers Do. Cambridge, MA: Harvard University Press.

Boyer Commission on Educating Undergraduates in the Research University. 1998. Reinventing Undergraduate Education: A Blueprint for America's Research Universities. Stanford, CA: Carnegie Foundation for the Advancement of Teaching.

Brew, Angela. 2006. Research and Teaching: Beyond the Divide. New York: Palgrave.

Brew, Angela. 2013. "Understanding the Scope of Undergraduate Research: A Framework for Curricular and Pedagogical Decision-making." Higher Education 66: 603-618. doi: 10.1007/s10734-013-9624-x

Brownell, Jayne Elise, and Lynn Ellen Swaner. 2010. Five High-impact Practices: Research on Learning Outcomes, Completion, and Quality. Washington, DC: Association of American Colleges \& Universities.

Burnette, James M., III, and Susan R. Wessler. 2013. "Transposing from the Laboratory to the Classroom to Generate Authentic Research Experiences for Undergraduates." Genetics 193: 367-375. doi: 10.1534/genetics.112.147355

Conrad, Clifton, and Laura Dunek. 2012. Cultivating Inquiry-Driven Learners: A College Education for the Twenty-First Century. Baltimore: Johns Hopkins University Press.

Council on Undergraduate Research. 2016. "Fact Sheet." About CUR. http:// www.cur.org/about_cur/

Davis, Dannielle Joy. 2007. "Access to Academe: The Importance of Mentoring to Black Students." Negro Education Review 58: 217-231.

Gregerman, Sandra R. 2009. "Filling the Gap: The Role of Undergraduate Research in Student Retention and Academic Success." In Broadening Participation in Undergraduate Research: Fostering Excellence and Enhancing the Impact, ed. Mary K. Boyd and Jodi L. Wesemann, 245-256. Washington, DC: Council on Undergraduate Research.

Handelsman, Jo, Christine Pfund, Sarah Miller Lauffer, and Christine Maidl Pribbenow. 2005. Entering Mentoring: A Seminar to Train a New Generation of Scientists. Madison: University of Wisconsin Press.
Healey, Mick, and Alan Jenkins. 2009. Undergraduate Research and Inquiry. York, UK: Higher Education Academy.

Healey, Mick, Alan Jenkins, and John Lea. 2014. Developing Research-based Curricula in College-based Higher Education. York, UK: Higher Education Academy.

Jones, Melanie T., Amy E. L. Barlow, and Merna Villarejo. 2010. "Importance of Undergraduate Research for Minority Persistence and Achievement in Biology." Journal of Higher Education 81(1): 82-115. doi: 10.1353/jhe.0.0082

Jones, Rebecca M., and Shannon N. Davis. 2014. “Assessing Faculty Perspectives on Undergraduate Research: Implications from Studies of Two Faculties." CUR Quarterly 34(3): 37-42.

Karukstis, Kerry. 2012. "Pivotal Junctures in the Undergraduate Research Enterprise." CUR Quarterly 33(1): 14-19.

Karukstis, Kerry, and Timothy Elgren. 2007. Developing and Sustaining a Research-supportive Curriculum: A Compendium of Successful Practices. Washington, DC: Council on Undergraduate Research.

Kinkead, Joyce. 2003. "Learning through Inquiry: An Overview of Undergraduate Research." New Directions for Teaching and Learning 93: 5-13. doi: $10.1002 / \mathrm{tl} .85$

Kuh, George D. 2008. High-impact Educational Practices: What They Are, Who Has Access to Them, and Why They Matter. Washington, DC: Association of American Colleges \& Universities.

Larson, Susan. 2016. "From CUR's President." CUR Quarterly 37(1): 2. doi: $10.18833 /$ curq/37/1/12

Lopatto, David. 2010. "Undergraduate Research as a High-impact Student Experience." Peer Review 12(2): 27-30.

Malachowski, Mitchell. 1996. "The Mentoring Role in Undergraduate Research Projects." CUR Quarterly 17(2): 91-93, 105-106.

Malachowski, Mitchell, Nancy Hensel, Elizabeth Ambos, Kerry Karukstis, and Jeffrey Osborn. 2014. "The Evolution of CUR Institutes: From Serving Individuals to Serving Campuses, Systems, and Consortia." CUR Quarterly 35(1): 34-35.

Merkel, Carolyn A., and Shenda M. Baker. 2002. How to Mentor Undergraduate Researchers. Washington, DC: Council on Undergraduate Research.

Mitten, Carolyn, and Dorene Ross. 2016. "Sustaining a Commitment to Teaching in a Research-Intensive University: What We Learn from Award-Winning Faculty." Studies in Higher Education: 1-14. doi: 10.1080/03075079.2016.1255880

National Academy of Sciences, National Academy of Engineering, and Institute of Medicine. 1997. Adviser, Teacher, Role Model, Friend: On Being a Mentor to Students in Science and Engineering. Washington, DC: National Academies Press.

Osborn, Jeffery M., and Kerry Karukstis. 2009. "The Benefits of Undergraduate Research, Scholarship, and Creative Activity." In Broadening Participation in Undergraduate Research: Fostering Excellence and Enhancing the Impact, ed. Mary K. Boyd and Jodi Lynn Wesemann, 41-53. Washington, DC: Council on Undergraduate Research.

Rowlett, Roger, Linda Blockus, and Susan Larson. 2012. "Characteristics of Excellence in Undergraduate Research." Characteristics of Excellence in Undergraduate Research (COEUR), ed. Nancy Hensel, 2-19. Washington, DC: Council on Undergraduate Research. 
Shanahan, Jenny O. 2012. "Building Undergraduate Research into the Curriculum." Faculty Support and Undergraduate Research: Innovations in Faculty Role Definition, Workload, and Reward, ed. Nancy H. Hensel and Elizabeth L. Paul, 68-76. Washington, DC: Council on Undergraduate Research.

Shanahan, Jenny O., Elizabeth Ackley-Holbrook, Eric Hall, Kearsley Stewart, and Helen Walkington. 2015. "Ten Salient Practices of Undergraduate Research Mentors: A Review of the Literature." Mentoring and Tutoring: Partnership in Learning 23: 359-376.

Shellito, Cindy, Kalyn Shea, Gary Weissmann, Anke Mueller-Solger, and William Davis. 2001. "Successful Mentoring of Undergraduate Researchers: Tips for Creating Positive Student Research Experiences." Journal of College Science Teaching 30: 460-464.

Shore, Cecilia. 2005. “Toward Recognizing High-quality Faculty Mentoring of Undergraduate Scholars." Journal of Excellence in College Teaching 16(2): 111-136.

Strauss, Anselm, and Juliet Corbin. 1990. Basics of Qualitative Research: Grounded Theory Procedures and Techniques. Newbury Park, CA: SAGE Publications.

Thiry, Heather, and Sandra L. Laursen. 2011. "The Role of the Student-advisor Interactions in Apprenticing Undergraduate Researchers into a Scientific Community of Practice." Journal of Science Education and Technology 20: 771-784. doi: 10.1007/s10956-010-9271-2

Walkington, Helen, Amy Griffin, Lisa Keys-Matthews, Sandra Metoyer, Wendy Miller, Richard Baker, and Derek France. 2011. "Embedding Researchbased Learning Early in the Undergraduate Geography Curriculum." Journal of Geography in Higher Education, 35: 315-330.

Wenzel, Thomas J. 1997. "What Is Undergraduate Research?” CUR Quarterly 17(4): 163.

Willison, John W. 2009. "Multiple Contexts, Multiple Outcomes, One Conceptual Framework for Research Skill Development in the Undergraduate Curriculum." CUR Quarterly 29(3): 10-14.

Willison, John W. 2012. "When Academics Integrate Research Skill Development in the Curriculum." Higher Education Research \& Development 31: 905-919. doi: 10.1080/07294360.2012.658760

Willison, John, and Kerry O’Regan. 2007. “Commonly Known, Commonly Not Known, Totally Unknown: A Framework for Students Becoming Researchers." Higher Education Research and Development 26: 393-409.

Yaffe, Kristen, Carol Bender, and Lee Sechrest. 2012. "What Is a Mentor?” CUR Quarterly 33(2): 34-39.

\section{Jenny Olin Shanahan}

\section{Bridgewater State University, jshanahan@bridgew.edu}

Jenny Olin Shanahan is director of undergraduate research at Bridgewater State University in Massachusetts. A CUR Councilor since 2008, she served on the CUR Executive Board from 2014 to 2016. Shanahan has coedited two books and authored eleven articles and book chapters on undergraduate research, as well as presented dozens of talks and faculty workshops across the United States and Canada. She speaks most often about ensuring equitable access to high-impact practices for all students, embedding research and inquiry in the curriculum, creating faculty-student collaborations in the arts and humanities, and supporting excellent faculty mentorship.

Helen Walkington is professor in higher education at Oxford Brookes University, UK. She is a National Teaching Fellow (2009) and Principal Fellow of the Higher Education Academy (2012). Walkington has written papers, chapters, books, and guides relating to teaching and learning in higher education. She has established undergraduate research conferences and journals and has been a steering group member of the British Conference of Undergraduate Research (BCUR) since its inception in 2010. She is editor-in-chief of the undergraduate research journal GEOverse, associate editor of Higher Education Pedagogies, and editorial board member of the Journal of Geography in Higher Education.

Elizabeth Ackley is associate professor of health and exercise science, and Brian H. Thornhill Endowed Chair at Roanoke College in Salem, Virginia. Her research interests involve relationships between infrastructure (social and environmental) and population health. By prioritizing a translational research approach, her work has led to numerous redevelopment efforts in mid-sized communities targeting neighborhood-level health inequities. Ackley's research is supported by the Robert Wood Johnson Foundation, Reinvestment Fund, and the Virginia Foundation for Healthy Youth.

Eric E. Hall is professor of exercise science and the faculty athletics representative at Elon University in North Carolina. His primary interest is in exercise neuroscience, which includes research and education in the area of physical activity and mental health and also explores the impact of concussions in student-athletes at the high school and collegiate levels. Hall has authored more than 50 research articles and 6 book chapters and has coedited a book. At his institution he has received awards for his mentorship and scholarship.

Kearsley A. Stewart is Professor of the Practice at Duke University with appointments in global health and cultural anthropology. She previously taught at Northwestern University, worked at the Centers for Disease Control in Atlanta as a behavioral scientist, and was a postdoctoral fellow at the Harvard Center for Population and Development Studies. Stewart's research interests include research ethics of HIV/AIDS clinical trials in Africa and global health pedagogy. Her research is supported by NIH, NSF, and Fulbright grants. She currently teaches graduate and undergraduate courses in global health research ethics, ethics of infectious disease, narrative methods in HIV/AIDS research, and qualitative global health research methods.

\section{doi: $10.18833 /$ curq/37/4/14}

